\title{
Malabarismos e ilusionismos na realização de um projeto interdisciplinar
}

\author{
Silvana Mariani Hueblin
}

\begin{abstract}
Este relato de experiência conta como nasceu e se desenvolveu o espetáculo 'O circo vem aí!', realizado com uma turma de segunda série do ensino fundamental, de uma escola pública da cidade de Florianópolis. 0 projeto foi elaborado para a realização do estágio curricular supervisionado do Curso de Licenciatura em Educação Artística - Habilitação em Música, da Universidade do Estado de Santa Catarina. As canções, com temas circenses, foram extraídas do repertório da música popular brasileira e inspiraram a confecção do cenário e o figurino de cada um dos personagens, possibilitando assim o trabalho interdisciplinar entre música, artes plásticas e cênicas.
\end{abstract}

\section{O circo vem aí....}

Durante o período de abril a novembro de 2003, os alunos da segunda série do ensino fundamental, na faixa etária entre oito e nove anos, da Escola de Educação Básica Simão José Hess, tiveram a oportunidade de se transformar em artistas de circo. 0 projeto 'O circo vem aí" foi elaborado pela aluna estagiária do curso de Licenciatura em Música da UDESC ${ }^{2}$ juntamente com uma das professoras de artes da escola ${ }^{3}$.

O projeto de educação musical, elaborado para a realização do estágio curricular supervisionado, teve como objetivo proporcionar aos alunos um contato com composições brasileiras focando temas circenses. Por um lado, foram

1 As expressões como 'O circo vem aí', 'sem coração' e 'despencar do céu' que, posteriormente, aparecerão no texto são palavras retiradas de letras de músicas do repertório utilizado.

2 Silvana Mariani Hueblin.

3 Renata Moraes Callado de Aquino. 
realizadas atividades de canto e execução instrumental utilizando instrumentos de percussão como caxixis, agogôs, reco-recos, clavas, triângulos, entre outros. De outro lado, foram desenvolvidas atividades de expressão corporal e de criação do cenário e do figurino de cada um dos personagens, contando com a participação dos alunos, individualmente e em grupo.

Durante o primeiro semestre, os alunos participaram de uma série de exercícios e jogos fundamentados nos princípios educacionais de Dalcroze ${ }^{4}$ onde o elemento central é o próprio corpo que vive, expressa e se desenvolve. Esta pedagogia educacional está baseada no desenvolvimento integral do ser humano, envolvendo corpo, mente, espírito, sensibilidade, movimento e conhecimentos musicais (Dalcroze, 1965).

As relações de tempo, espaço e energia, base do pensamento Dalcroziano, foram vivenciadas em sala de aula, partindo de elementos musicais contidos no próprio repertório. As crianças foram estimuladas a conhecer os limites corporais e a explorar o espaço através de exercícios rítmicos, tímbricos e melódicos. Ainda que o trabalho não se restringiu a utilizar qualquer método de educação musical, podemos afirmar que idéias advindas de outras experiências educacionais foram referência na construção deste projeto de educação musical, realizado durante o período de estágio curricular supervisionado.

O tema 'circo' foi escolhido devido às múltiplas possibilidades artísticas que oferece, como a música, o movimento, a interpretação e a possível criação do figurino. 0 resultado foi um projeto interdisciplinar, onde a música, as artes plásticas e as artes cênicas entraram no picadeiro.

4 Émile Jaques-Dalcroze (1865-1950): músico-pedagogo suiço. 
Conforme Richter (2002, p.85) um trabalho interdisciplinar "indica a inter-relação entre duas ou mais disciplinas, sem que nenhuma se sobressaia sobre as outras, mas que se estabeleça uma relação de reciprocidade e colaboração, com o desaparecimento de fronteiras entre as áreas do conhecimento". Foi seguindo essa idéia de interrelação entre as áreas e entre os saberes já inerentes em cada um dos participantes - alunos, professores e pessoas da comunidade - que o trabalho foi tomando forma a cada semana.

\section{Vai, vai, vai começar \\ a brincadeira....}

Na música popular brasileira encontramos inúmeras canções com temas circences compostas por artistas de renome como Chico Buarque de Holanda e Edu Lobo, Toquinho e Vinícius, mas também por velhos palhaços como Arrelia ${ }^{5}$. Pesquisando o repertório com letras referentes ao circo, além de outros puramente instrumentais como a suíte circense de Jürg Kindle ${ }^{6}$, selecionamos canções como: Ciranda da bailarina (Edu Lobo e Chico Buarque), O Circo vem aí (Haroldo Lobo Milton de Oliveira e Carvalhinho), Piruetas (Chico Buarque, L. Enrique Bacalov Sérgio Bardottti), entre outras.

Dessa forma, fomos apresentando aos alunos os fascinantes personagens do circo, como os engolidores de fogo, acrobatas, malabaristas, bailarinas, dançarinos da corda bamba, trapezistas, palhaços, mágicos, domadores de leões e elefantes. A charanga, lugar onde ficam os músicos

5 Arrelia (1905-): famoso palhaço de circo que durante vinte e um anos apresentou-se na TV Record com o "Circo Arrelia". Criou e gravou músicas para o carnaval e para o circo, entre elas o "Como vai, como vai, como vai?".

6 Jürg Kindle, compositor suíço. 
do circo, foi nosso espaço para conhecermos e manusearmos os instrumentos musicais.

Caminhar como os elefantes em compasso binário, utilizando notas longas e curtas, foi a nossa forma de vivenciar o ritmo. Andar na corda bamba, para frente e para trás, conforme o comportamento da melodia, era nossa maneira de fazer um solfejo corporal. Acordes dissonantes nos levaram a penetrar no mistério da bola de cristal. Procurar um coelho dentro da cartola obedecendo a pulsação e somente encontrá-lo no acorde final, foi um desafio para o mágico. Cantar, brincar, pular e dançar conforme a música foi a nossa brincadeira.

Uma vez inseridos na paisagem sonora do circo, os próprios alunos foram escolhendo os seus personagens, assim como elaborando os figurinos através de desenhos realizados em sala de aula, sob a orientação da professora de artes da turma.
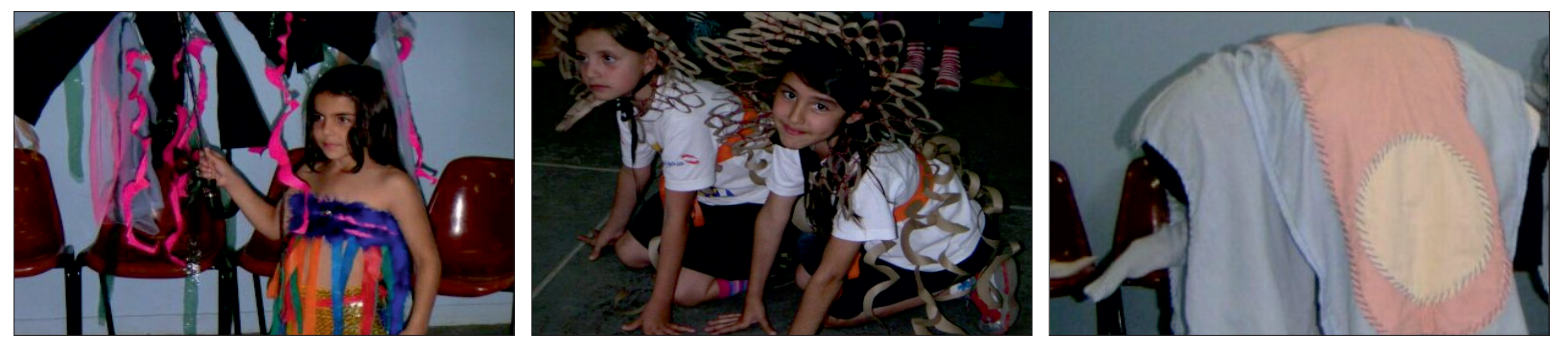

\section{Uma pirueta, duas piruetas, bravo, bravo!...}

De acordo com Bolognesi "acrobacias, malabarismos, equilibrismos e ilusionismos diversos deixam evidente a capacidade humana de superação dos seus próprios limites" (2003, p.13). Mas para quê superar esses limites? No nosso entender, simplesmente para aumentar a autoestima, tão evidentemente baixa nos alunos que 
tínhamos conosco, mas que à medida que o nosso circo avançava, iam brilhando como estrelas.

'Uma pirueta, duas piruetas, vamos lá'... porém, sem ferir o colega, percebendo o espaço existente, a energia necessária e o tempo para agir. Como afirma Bolognesi "o circo é a exposição do corpo humano em seus limites biológico e social" (2003, p.13). Experimentar os limites, o possível e o impossível, aprender a respeitar o colega e entender que o que acontece no picadeiro é responsabilidade de todos. Nossa tarefa não foi somente a de musicalizar, mas também a de socializar.

Neste sentido, entendemos que a educação deve também se preocupar com o desenvolvimento físico, intelectual, afetivo, moral e social da criança. O contato com o outro através do canto em grupo e das coreografias criadas para o espetáculo, por exemplo, foram formas de conduzir a criança a entender que ela é um elemento de um todo e ao mesmo tempo um elemento indispensável, sem o qual o grupo poderia ser rompido.

\section{Quem chora tem que rir, Com tanta palhaçada...}

Uma vez conhecido o repertório, as próprias letras das canções serviram de inspiração para a confecção do cenário e do figurino. Caixinhas de leite foram se transformando em flores nas mãos da professora de artes. Uma garrafa de refrigerante com uma flor pingente se transformou num chapéu de palhaço. O copinho de iogurte virou nariz de palhaço. Tecidos de tnt recortados viraram coloridas roupas de bailarinas com detalhes de estrelas brilhantes (feitas com caixinha de leite). Pedaços de computador e fios de metal passaram a ser as veias de metal de um robô 'sem coração'. Bambolês abandonados na escola serviram de armação para as enormes patalonas de palhaços 
coloridos e cheios de movimento. E, um guardachuva velho e rasgado, repleto de penduricalhos, virou a sombrinha da dançarina da corda bamba.

0 engolidor de fogo, o faquir que come pregos, a mulher que engole espada ganharam objetos feitos com rolos de papel de cozinha e ornamentados com fitinhas, plumas, papéis de celofane. As enormes jubas dos leões foram feitas com rolinhos de papel higiênico e os elefantes, animais imensos que dançavam ao som de uma música indiana, vinham escondidos embaixo dos lençóis velhos que se transformaram em orelhas, trombas e notas musicais. Sob a orientação da professora de artes, os alunos, desenhando e pintando os seus próprios personagens, participaram do processo de criação e maturação


do espetáculo.

\section{O espetáculo não pode parar...}

Os riscos dos artistas do circo são muito grandes. A equilibrista pode cair da corda bamba, o trapezista pode 'despencar do céu', o palhaço pode não saber de onde arrancar sorrisos e as bailarinas podem virar as pontas dos pés. A mulher da bola de cristal pode nos revelar algo de nosso futuro que não queremos ouvir. $O$ domador de leões pode não conter as feras. E daí? O que faremos? Não importa. 
0 público participa do suor do artista. 0 público bate palmas e canta junto as canções, o público teme pelo fracasso do colega, mas tem esperança que esse vai se superar. Como destaca Bolognesi (2003, p.14) "se o artista falha, ele é aplaudido porque ao menos tentou. Ele ousou, e isso já é o bastante para impulsionar a fantasia coletiva da superação". Foi com essa emoção que o público voltou para casa, carregando nos olhos as imagens de um espetáculo mágico, feito pelos próprios colegas, crianças iguais a eles que, por um dia, se transformaram em artistas, num circo montado na escola pública.

Movidos por situações concretas vividas no contexto escolar, procuramos transformar a realidade através de ações coletivas e de respeito mútuo. A individualidade e potencialidade dos integrantes do grupo, constituído por alunos, professores, músicos e pessoas da comunidade, possibilitaram a realização deste espetáculo.

A realização deste projeto interdisciplinar nos possibilitou contar com escolhas e alternativas para a solução de problemas, tanto a nível pedagógico como metodológico. Unir os saberes das diferentes áreas em prol da criatividade e da educação pôde romper com a concepção fragmentária do conhecimento. Foi necessário unir as partes envolvidas para alcançar o todo, pois estas isoladamente perderiam seu valor. Desta forma, acreditamos que é possível a realização de projetos interdisciplinares.

\section{Referências Bibliográficas}

BOLOGNESI, Mário Fernando. Palhaços. São Paulo: Editora da Unesp, 2003.

JAQUES-DALCROZE, Émile. Le rythme, la musique et l'éducation. Suisse: Edition Foetisch, 1965.

RICHTER, Ivone Mendes. Multiculturalidade e Interdisciplinaridade. In: Barbosa, Anamae (org.). 